\title{
Using Clumped Isotope Systems and Modeling to Study Dissolved Inorganic Carbon Transformation in Waters at the Cedars \\ ZEESHAN ANJUM PARVEZ
}

University of California, Los Angeles

Presenting Author: zeeshan.parvez@outlook.com

Climate change is an ever-growing concern that threatens our collective future. With the rapid input of greenhouse gases into the atmosphere, we are now at a point where the reduction of greenhouse gas emissions needs to be coupled with active removal to prevent the global average temperature increase from exceeding model predictions of 1.5 to $2{ }^{\circ} \mathrm{C}$. A technique that is being explored for carbon sequestration involves exploiting favorable chemical reactions that remove it from the atmosphere. While there are many forms of carbon sequestration that have been proposed, in-situ sequestration shows promise as it involves minimal processing and infrastructure, and involves the dissolution of $\mathrm{CO} 2$ into water which is in contact with bodies of ultramafic rock such as peridotite bodies, where it is transformed and sequestered in peridotite through serpentinization. Here we build on a published framework for using the analysis of paired carbonate clumped isotope isotopolouges $(\Delta 47$ and $\Delta 48)[1]$ to investigate dissolved inorganic carbon (DIC) transformation at sites where peridotite is known to undergo serpentinization, and use novel measurements combined with isotopic modeling to study the fate and transformation of dissolved inorganic carbon (DIC). Results confirm absorption-dominant disequilibria processes at several sites and are consistent with a hydroxylation dominant pathway for the conversion of $\mathrm{CO} 2$ into $\mathrm{HCO} 3-$. 